This item was submitted to Loughborough's Research Repository by the author.

Items in Figshare are protected by copyright, with all rights reserved, unless otherwise indicated.

\title{
Does normalization of voluntary EMG amplitude to MMAX account for the influence of electrode location and adiposity?
}

PLEASE CITE THE PUBLISHED VERSION

https://doi.org/10.1111/sms.13270

\section{PUBLISHER}

(c) Wiley

\section{VERSION}

AM (Accepted Manuscript)

\section{PUBLISHER STATEMENT}

This work is made available according to the conditions of the Creative Commons Attribution-NonCommercialNoDerivatives 4.0 International (CC BY-NC-ND 4.0) licence. Full details of this licence are available at: https://creativecommons.org/licenses/by-nc-nd/4.0/

\section{LICENCE}

CC BY-NC-ND 4.0

\section{REPOSITORY RECORD}

Lanza, Marcel Bahia, Thomas G. Balshaw, Garry J. Massey, and Jonathan P. Folland. 2019. "Does Normalization of Voluntary EMG Amplitude to MMAX Account for the Influence of Electrode Location and Adiposity?". figshare. https://hdl.handle.net/2134/34297. 


\section{TITLE PAGE}

Title:

Does normalization of voluntary EMG amplitude to $\mathrm{M}_{\mathrm{MAX}}$ account for the influence of electrode location and adiposity?

\section{Authors:}

Marcel B. Lanza ${ }^{1,2}$, Thomas G. Balshaw ${ }^{1}$, Garry J. Massey ${ }^{1}$, Jonathan P. Folland ${ }^{1}$.

\section{Affiliations:}

${ }^{1}$ School of Sport, Exercise, and Health Sciences, Loughborough University, Leicestershire, UK.

${ }^{2}$ CAPES Foundation, Ministry of Education of Brazil, Brasilia - DF 70040-020, Brazil.

\section{Abbreviated title for running head:}

EMG amplitude with location and adiposity

\section{Corresponding author:}

Marcel B. Lanza

+44 07761318103

School of Sport, Exercise, and Health Sciences, Loughborough University, Leicestershire, UK, LE11 3TU. Email: marcel.lanza@gmail.com / work telephone: +447761318103. 


\section{ABSTRACT}

Voluntary surface electromyography (sEMG) amplitude is known to be influenced by both electrode position and subcutaneous adipose tissue thickness, and these factors likely compromise both between- and within-individual comparisons. Normalization of voluntary sEMG amplitude to evoked maximum M-wave parameters [ $\mathrm{M}_{\mathrm{MAx}}$ peak-to-peak (P-P) and Area] may remove the influence of electrode position and subcutaneous tissue thickness. The purpose of this study was to: (i) assess the influence of electrode position on voluntary, evoked (MMAX P-P and Area) and normalized sEMG measurements across the surface of the vastus lateralis (VL; experiment 1: $n=10$ ); and (ii) investigate if $\mathrm{M}_{\mathrm{MAX}}$ normalization removed the confounding influence of subcutaneous tissue thickness [muscle-electrode distance (MED) from ultrasound imaging] on sEMG amplitude (experiment 2; $n=41$ ). Healthy young men performed maximum voluntary contractions (MVCs) and evoked twitch contractions during both experiments. Experiment 1: voluntary sEMG during MVCs was influenced by electrode location $(\mathrm{P} \leq 0.046$, ES $\geq 1.49$ "large”), but when normalized to M MAX P-P showed no differences between VL sites $(\mathrm{P}=0.929)$ which was not the case when normalized to $\mathrm{M}_{\mathrm{MAX}}$ Area $(\mathrm{P}<0.004)$. Experiment 2: voluntary sEMG amplitude was related to MED, which explained 31-38\% of the variance. Normalization of voluntary sEMG amplitude to $\mathrm{M}_{\mathrm{MAX}} \mathrm{P}-\mathrm{P}$ or $\mathrm{M}_{\mathrm{MAX}}$ Area reduced but did not consistently remove the influence of MED which still explained up to $16 \%$ ( $\left.\mathrm{M}_{\mathrm{MAX}} \mathrm{P}-\mathrm{P}\right)$ and 23\% ( $\mathrm{M}_{\mathrm{MAX}}$ Area) of the variance. In conclusion, M MAX P-P was the better normalization parameter for removing the influence of electrode location and substantially reduced but did not consistently remove the influence of subcutaneous adiposity.

\section{Key Words}

sEMG; sEMG Normalization; Maximal m-wave; Spatial location; Muscle-Electrode Distance. 


\section{INTRODUCTION}

Surface electromyography (sEMG) is used for a range of important applications within physiology and biomechanics, including measurement of neuromuscular activation ${ }^{1}$ and detection of neuromuscular disorders ${ }^{2}$. In these different contexts, sEMG amplitude is often employed to assess the changes within individuals and/or the differences between individuals. However, the influence of a range of both extrinsic (e.g. electrode position) and intrinsic (e.g. subcutaneous fat) factors can confound sEMG measurements ${ }^{1}$ and may compromise both between- and within-individual comparisons.

Voluntary sEMG amplitude is known to vary with electrode location across the surface of a muscle ${ }^{3-5}$ and thus even minor differences in placement (between-days or -researchers) may influence sEMG measurements. In addition, intrinsic factors such as subcutaneous fat thickness can also influence the measurement of sEMG amplitude during voluntary contractions. Specifically, muscle-electrode distance (MED) has been found to be inversely related to sEMG amplitude ${ }^{6-8}$ due to the high electrical resistance of adipose tissue ${ }^{8}$. It is currently unknown if evoked sEMG responses vary with electrode location and MED in a similar way to voluntary sEMG amplitude. If this were the case then normalization of voluntary sEMG amplitude to evoked responses may remove the influence of electrode location and MED, but this has not been investigated.

The use of an evoked supra-maximal compound muscle action potential (M MAX) has emerged as a promising way of normalizing sEMG amplitude during voluntary contractions due to the highly controlled and involuntary nature of $\mathrm{M}_{\mathrm{MAX}}$. Furthermore, $\mathrm{M}_{\mathrm{MAx}}$ may be particularly useful as an independent reference for normalisation of sEMG during maximum voluntary isometric contractions (MVCs); given that the most widely used voluntary reference task (MVCs) are not valid in this case (i.e. a variable normalized to itself) ${ }^{9,10}$. Both $\mathrm{M}_{\mathrm{MAX}}$ 
amplitude (i.e. peak-to-peak, $\mathrm{M}_{\mathrm{MAX}} \mathrm{P}-\mathrm{P}$ ) and area ( $\mathrm{M}_{\mathrm{MAX}}$ Area), which is dependent on both amplitude and duration of the evoked potentials ${ }^{11}$, have been suggested/used as reference normalization measurements for voluntary sEMG ${ }^{9,10,12,13}$. Although $\mathrm{M}_{\mathrm{MAx}}$ normalization of voluntary sEMG has been demonstrated to reduce between-participant variability ${ }^{9}$ it is currently unknown if $\mathrm{M}_{\mathrm{MAx}}$ normalization of voluntary EMG recordings: (1) removes the influence of electrode location across the surface of the muscle on voluntary sEMG amplitude, and (2) removes the influence of MED on voluntary sEMG amplitude between-participants.

Therefore, the first purpose of this study was to assess the influence of electrode positioning on voluntary and evoked sEMG amplitude [root mean square (RMS) during MVC; and $\mathrm{M}_{\mathrm{MAX}} \mathrm{P}-\mathrm{P}$ and Area], and the proportionality of these measures, using multiple recording sites across the surface of the vastus lateralis (VL) (experiment 1). The second purpose was to investigate if $\mathrm{M}_{\mathrm{MAx}}$ normalization removed the confounding influence of body fat, measured as MED (via 2D ultrasonography), on sEMG amplitude during MVCs (experiment 2). Our first hypothesis was that voluntary sEMG and $\mathrm{M}_{\mathrm{MAX}} \mathrm{P}-\mathrm{P}$ and Area would change in proportion across the surface of the VL, thus, normalized voluntary sEMG amplitude (to MMAx) would remove the confounding effect of electrode location. Our second hypothesis was that $\mathrm{M}_{\mathrm{MAX}}$ normalization would remove the inverse relationship between voluntary surface EMG amplitude and MED.

\section{MATERIALS AND METHODS}

\section{Participants}

Healthy, recreationally active, young males with no previous lower-body injuries and no systematic strength training participation for $>12$ months took part in both experiments. Experiment one: $n=10$; age, $22 \pm 2$ y; height, $1.78 \pm 0.07$ m; body mass, $73 \pm 5 \mathrm{~kg}$; body mass 
index, $24 \pm 2 \mathrm{~kg} / \mathrm{m}^{2}$. Experiment two: $n=41$; age, $24 \pm 2$ y; height, $1.76 \pm 0.06 \mathrm{~m}$; body mass, $69 \pm 6 \mathrm{~kg}$; body mass index, $22 \pm 1 \mathrm{~kg} / \mathrm{m}^{2}$. The Loughborough University Ethics committee approved both experiments and participants provided written informed consent prior to their participation.

\section{Overview}

Participants reported for three laboratory sessions at a consistent time of day for both experiment one (sessions 3-6 days apart) and experiment two (sessions 7-10 days apart) and were instructed to avoid strenuous exercise in the $48 \mathrm{~h}$ prior to each session. In each experiment, the first laboratory session was used as familiarisation, followed by two main measurement sessions. All sessions involved isometric voluntary and evoked twitch contractions of the dominant knee extensors whilst seated in a rigid custom-built adjustable testing chair with knee and hip joint angles as follows: experiment 1 , knee joint angle $=80^{\circ}$, hip joint angle $=54^{\circ}$; experiment 2, knee joint angle $=65^{\circ}$, hip joint angle $=54^{\circ}$ (where $0^{\circ}$ is full extension). The main measurement sessions involved a series of brief sub-maximum warm-up contractions followed by MVCs and evoked twitch contractions (via transcutaneous femoral nerve stimulation). During the main measurement sessions, sEMG recordings were made from six recording sites across the surface of the VL (Experiment 1) or from a single recording site over each of the superficial quadriceps [VL, vastus medialis (VM), rectus femoris (RF); Experiment 2]. Experiment 2 also involved B-mode ultrasound measurements of MED at each of the sEMG recording sites over the individual quadriceps muscles, whilst participants were at rest in the testing apparatus.

\section{Recording Procedures}

Torque and sEMG recordings 
Participants were securely strapped to the rigid isometric testing chair at the waist and across the chest to minimise extraneous bodily movement during all tasks. Force production was measured with a calibrated S-beam strain-gauge (linear range from 0-1500N, Force Logic, Swallowfield, UK). The strain gauge was attached to the participant using a custom reinforced non-extendable webbing strap (35 mm width) fastened $\sim 3 \mathrm{~cm}$ superior to the lateral malleolus perpendicular to the participant's lower leg. Force was sampled and recorded at 2,000 Hz using an analogue-to-digital (A/D) converter (Micro 1401, CED, Cambridge, UK) and PC utilising Spike 2 software (CED, Cambridge, UK). The force signal was low-pass filtered at $500 \mathrm{~Hz}$ with a fourth-order zero-lag Butterworth, digital filter (baseline noise: $<0.2 \mathrm{~N}$ ) and then gravity correction was applied by subtracting baseline force, before multiplying by lever length (the distance between the knee joint centre and the middle of the webbed strap) to calculate torque values.

Following skin preparation (shaving, abrading, and cleansing with 70\% ethanol) single differential (bipolar) wireless Trigno Standard sEMG sensors (Trigno, Delsys, Inc., Boston, MA; 1-cm inter-electrode distance) were placed at set percentages of thigh length (distance from knee joint space to the greater trochanter) parallel to the presumed orientation of the underlying fibres. Trigno wireless sensors have a built-in system with reference sensors in the same electrode, hence, no ground electrode is necessary. Sensors were secured to the skin using adhesive interfaces. For experiment one six sensors, organised in two rows of three sensors [anterior (A) or posterior (P)], were attached over the VL. The two parallel rows of sEMG electrodes were aligned along the long axis of the muscle at $30 \%$ (anterior row) and $\sim 70 \%$ (posterior row; Fig. 1) of the distance between the superficial anterior and posterior borders of the VL, respectively. The anterior and posterior borders of the VL muscles were assessed by palpation whilst participants contracted their quadriceps muscle. Sensors were placed at set percentages of thigh length (lateral knee joint centre to greater trochanter) from the superior 
border of the patella as follows: A1 (40\%), P1 (45\%), A2 (50\%), P2 (55\%), A3 (60\%) and P3 (65\%; Fig. 1). These sites were chosen to avoid the confounding influence of the innervation zone, in the most distal region of the VL ${ }^{4,14}$, on EMG signal amplitude ${ }^{3,15}$. For experiment two, sEMG sensors were placed in the centre of each constituent muscle belly at the following percentages of thigh length above the superior border of the patellar as follows: RF (65\%); VL (60\%); and VM (35\%). In both experiments, sEMG signals were amplified at source (x300; 20-to 450-Hz bandwidth) before further amplification (overall effective gain, x909) and subsequently sampled at 2,000 $\mathrm{Hz}$ using the same external (A/D) converter and computer software as the force recordings. During offline analysis, the sEMG data were time aligned with the force signal (inherent 48-ms delay of sEMG signal).

\section{Protocol}

Maximal voluntary contractions

Following a series of sub-maximum contractions performed at percentages of perceived maximum [50\% (x3), 75\% (x3), and 90\% (x1)] participants completed 2 (experiment 1) or 4 (experiment 2) MVCs. Participants were instructed to extend their knee by "pushing as hard as possible” for 3-5 s during MVCs with $\geq 30$ s recovery between each effort. Biofeedback was provided after the first MVC by displaying a horizontal cursor on the torque-time curve, displayed on a computer monitor in front of the participant, to indicate the greatest torque produced and encourage participants to produce greater torque with subsequent attempts. Additionally, verbal encouragement was given during all MVCs trials. Maximum voluntary torque (MVT) was the highest instantaneous torque during the MVCs, and RMS sEMG for each sensor was measured during a 500 ms epoch around MVT (250 ms either side of MVT; $\mathrm{EMG}_{\mathrm{MVT}}$ ), and absolute values from each individual sensor were then normalized to both the $\mathrm{M}_{\mathrm{MAX}} \mathrm{P}-\mathrm{P}$ and $\mathrm{M}_{\mathrm{MAX}}$ Area (see below) from the same sensor. 
Evoked twitch contractions and $M_{M A X}$ recordings

Transcutaneous femoral nerve stimulation was conducted, whilst the participant was voluntarily passive, by placing an anode (70 x 100 mm carbon rubber electrode; ElectroMedical Supplies, Greenham, UK) over the greater trochanter and a cathode (10 mm diameter, protruding 20 mm from a 35 x 55 mm plastic base; Electro-Medical Supplies, Greenham, UK) over the femoral nerve in the femoral triangle region, both were coated in conductive gel. Electrical stimulation was delivered with a constant current variable voltage stimulator (DS7AH, Digitimer Ltd., Welwyn Garden City, UK). The cathode was sequentially repositioned until the optimum cathode position was identified (highest twitch response to a constant low current stimuli), before being secured with transpore tape. Incremental single pulse stimuli were delivered (every $10 \mathrm{~s}, 15-20 \mathrm{~mA}$ increments) until peak twitch force and the peak-to-peak amplitude of the compound motor unit action potential (M-wave) plateaued for all recorded EMG sites. At least two further increments were delivered to ensure the plateau had been reached. Then three supra-maximal stimuli were delivered (10-15 s between each stimulus) at a current of $150 \%$ of the plateau level to measure supramaximal twitch force and M MAX P-P and Area.

Ultrasound Measurements (Experiment two only)

An ultrasound scanner [Hitachi EUB-8500, Northamptonshire, UK, 5-10 MHz linear array transducer (EUP-L53L), scanning width $92 \mathrm{~mm}$ ] was used to collect B-mode images of the thigh with the mid-point of the probe positioned over VL (60\% of thigh length), RF (65\% of thigh length) and VM (35\% of thigh length). Ultrasound images were recorded by a computer with ezcap video capture software (via an S-video to USB converter). Images were collected whilst participants were at rest in the same isometric testing apparatus used to record 
knee extension torque. MED was measured, using an open source Tracker software (version 4.92, physlets.org/tracker), as the distance from the surface of the skin to the muscle fascia (Fig. 2).

\section{Statistical analysis}

For both experiments the data from the main measurement sessions (session 2 and 3, excluding familiarisation) were averaged to enhance the reliability of the measurements, and statistical analysis was completed using SPSS version 22 (IBM Corporation, Armonk, New York, USA). The significance level was set at $P<0.05$ and data are reported as mean \pm SD. Due to both experiments having duplicate main sessions a within-participant coefficient of variation between sessions ( $\mathrm{CV}_{\mathrm{W}}$; $(\mathrm{SD} / \mathrm{mean}) \mathrm{x}$ 100) for twitch peak, MVT and EMGMVT data was calculated. $\mathrm{CV}_{\mathrm{W}}$ was quantified for each $\mathrm{SEMG}$ site (both experiments) but for experiment one individual $\mathrm{CV}_{\mathrm{W}}$ values from each measurement site were averaged across all six VL sites to provide an overall representation of the within-participant reliability of VL sEMG parameters that were measured. In addition, paired $t$-tests were used to confirm that there were no differences between the main measurement sessions. For experiment 1 , repeated measures general linear models (one-way ANOVA) were used to determine the effects of electrode position on voluntary, evoked, and normalized sEMG measures. When a main effect of electrode position was detected differences between recording sites were assessed using Bonferroni adjusted post-hoc tests. The standardized effect size (ES; Cohen`s d) are included and ES of $<0.2$ was considered "trivial", $\geq 0.2$ to $\leq 0.49$ "small", $\geq 0.5$ to $\leq 0.79$ "moderate" and $\geq 0.8$ "large" 16 .

For experiment 2, bivariate relationships between MED and the sEMG parameters (absolute and normalized) were assessed with Pearson's product moment correlations. As there

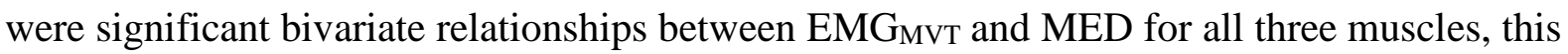


relationship was fitted with a quadratic function, which provided the best fit for the relationship

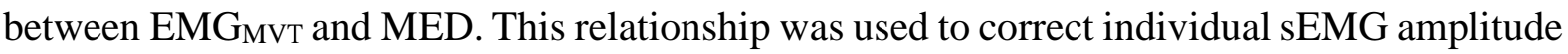
to MED measurements at that recording site. This involved summating the individual's residual, in comparison to the cohort relationship with MED (e.g. sEMG amplitude vs. MED), with the group mean for sEMG amplitude ${ }^{17}$. Between-participant coefficient of variation $\left[\mathrm{CV}_{\mathrm{B}}\right.$ (SD/Mean*100)] was calculated for absolute $\mathrm{EMG}_{\mathrm{MVT}}$ as well as $\mathrm{EMG}_{\mathrm{MVT}}$ normalized to $\mathrm{M}_{\mathrm{MAX}} \mathrm{P}-\mathrm{P}$ and $\mathrm{M}_{\mathrm{MAX}}$ Area, and MED corrected EMG $\mathrm{MVT}_{\mathrm{M}}$ for each of the 3 muscles.

\section{RESULTS}

\section{Reliability}

For experiment 1 , the mean $C V_{\mathrm{W}}$ value of the six VL sensors was $15.1 \%$ for absolute $\mathrm{EMG}_{\mathrm{MVT}}, 20.7 \%$ for $\mathrm{M}_{\mathrm{MAX}} \mathrm{P}-\mathrm{P}$, and $21.2 \%$ for $\mathrm{M}_{\mathrm{MAX}}$ Area respectively, with no differences detected between test sessions for any of these measurements $\left(t_{(9)} \geq-1.528, P \geq 0.139\right)$. For experiment 2, the range of $C V_{W}$ values of the 3 sites over the three superficial quadriceps (VM, VL, RF) were $14-17 \%, 14-16 \%$ and $14-19 \%$ for absolute EMG MVT, $_{\text {MAX }}$ P-P, and $\mathrm{M}_{\mathrm{MAX}}$ Area, respectively $\left(\mathrm{t}_{(40)} \geq-0.873, \mathrm{P} \geq 0.383\right)$.

Knee extension MVT torque presented a mean $\mathrm{CV}_{\mathrm{W}}$ value of $4.8 \%$ in experiment one and $2.9 \%$ in experiment two. Twitch peak torque presented an excellent $\mathrm{CV}_{\mathrm{W}}$ within experiment $1(0.6 \%)$ and experiment 2 (6.3\%). No differences were found between days in either experiment for MVT or Twitch peak torque $\left(\mathrm{t}_{(9)} \geq-1.191, \mathrm{P} \geq 0.094\right.$ for experiment one and $\mathrm{t}_{(40)} \geq-0.879, \mathrm{P} \geq 0.111$ for experiment two).

\section{Experiment one - Spatial Location}


There were differences in absolute $\mathrm{EMG}_{\mathrm{MVT}}$ between the six recording sites over the VL $\left(\mathrm{F}_{2,45}=7.273, \mathrm{P}<0.003\right)$ with specific differences as follows: A1 and A2 > P2 and P3 (Bonferroni $\mathrm{P} \leq 0.036, \mathrm{ES} \geq 1.63$ “large”); $\mathrm{P} 1>\mathrm{P} 3$ ( $\mathrm{P} \leq 0.046, \mathrm{ES} \geq 1.49$ “large”). The recording site with the highest EMG $\mathrm{MVT}_{\text {T }}$ amplitude (A1) was $42 \%$ higher than the site with the lowest value (P3; Table 1).

There were also differences in absolute $\mathrm{M}_{\mathrm{MAX}} \mathrm{P}-\mathrm{P}$ between sites $\left(\mathrm{F}_{2,45}=4.069, \mathrm{P}=\right.$ 0.004 ) and post-hoc tests revealed that $\mathrm{A} 1$ was greater than $\mathrm{P} 2$ (Bonferroni $\mathrm{P} \geq 0.024, \mathrm{ES} \geq 2.41$ "large") and A2 showed a tendency to be greater than P2 (Bonferroni $\mathrm{P}=0.070, \mathrm{ES}=2.33$ "large"; Fig. 3B) with a 51\% difference between the highest and the lowest site (Table 1). Similarly, absolute $\mathrm{M}_{\mathrm{MAX}}$ Area presented differences between sites $\left(\mathrm{F}_{2,45}=4.529, \mathrm{P}=0.020\right)$ with A1 and P3 > P2 (Bonferroni P $\leq$ 0.041, ES $\geq 1.37$ "large"; Fig. 3C), a tendency for A3 to be higher than P2 (Bonferroni $\mathrm{P} \leq 0.062, \mathrm{ES} \geq 0.86$ "large") and for A1 to be higher than P1 (Bonferroni $\mathrm{P} \leq 0.087, \mathrm{ES} \geq 1.23$ "large") with an overall 49\% difference between the sites with the highest and lowest $\mathrm{M}_{\mathrm{MAX}}$ Area values (Table 1).

In contrast, $\mathrm{EMG}_{\mathrm{MVT}}$ normalized to $\mathrm{M}_{\mathrm{MAX}} \mathrm{P}-\mathrm{P}$ showed no differences between the sites of VL $\left(\mathrm{F}_{2,45}=0.731, \mathrm{P}=0.929\right.$; Fig. 4), and therefore was not confounded by electrode location. However, EMG $\mathrm{MVT}_{\mathrm{T}}$ normalized to $\mathrm{M}_{\mathrm{MAX}}$ Area was different between the recording sites (up to $35 \% ; \mathrm{F}_{2,45}=4.083, \mathrm{P}=0.004$ ) and $\mathrm{P} 3$ was revealed to be smaller than A2 and P2 (Bonferroni $\mathrm{P} \leq 0.014, \mathrm{ES} \geq 1.1$ “large”).

\section{Experiment two - Subcutaneous tissue thickness}

As expected, there was an inverse relationship between absolute EMGMVT and MED for VM ( $\mathrm{r}=-0.62, \mathrm{n}=41, \mathrm{P}<0.001)$, RF $(\mathrm{r}=-0.62, \mathrm{n}=41, \mathrm{P}<0.001)$ and $\mathrm{VL}(\mathrm{r}=-0.68, \mathrm{n}=41$, $\mathrm{P}<0.001$; Fig. 5A). Thus, MED explained 31\% (VL) to 38\% (VM \& RF) of the variability in 


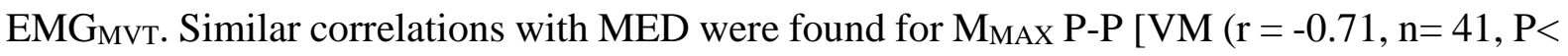
0.001), RF ( $r=-0.45, \mathrm{n}=41, \mathrm{P}<0.001)$ and VL $(\mathrm{r}=-0.68, \mathrm{n}=41, \mathrm{P}<0.001)]$ and $\mathrm{M}_{\mathrm{MAx}}$ area [VM $(r=-0.49, n=41, P<0.001), R F(r=-0.37, n=41, P=0.017)$ and VL $(r=-0.43, n=41, P<$ 0.001)]. When EMG $\mathrm{MVT}_{\mathrm{T}}$ was normalized to $\mathrm{M}_{\mathrm{MAX}} \mathrm{P}-\mathrm{P}$ there remained a relationship with MED for two of the three muscles, that was positive for the VM $(r=0.40, n=41, P=0.022$, Fig. $5 \mathrm{C})$ and negative for the $R F(r=-0.34, n=41, P=0.010)$, the exception being the VL where $\mathrm{EMG}_{\mathrm{MVT}}$ normalized to $\mathrm{M}_{\text {MAX }} \mathrm{P}-\mathrm{P}$ was unrelated to $\operatorname{MED}(\mathrm{r}=-0.25, \mathrm{n}=41, \mathrm{P}=0.106)$. Hence, while

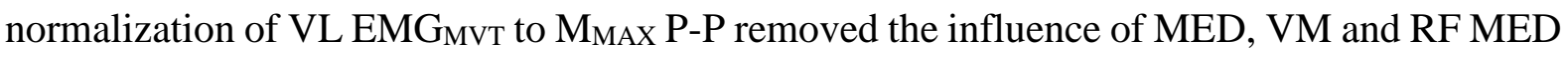
still accounted for $12-16 \%$ of the between-participant variability in normalized sEMG amplitude. When $\mathrm{EMG}_{\mathrm{MVT}}$ was normalized to $\mathrm{M}_{\mathrm{MAX}}$ Area a significant negative relationship remained for $\mathrm{RF}(\mathrm{r}=-0.48, \mathrm{n}=41, \mathrm{P}<0.001)$ and $\mathrm{VL}(\mathrm{r}=-0.44, \mathrm{n}=41, \mathrm{P}<0.010)$ with $\mathrm{MED}$, but for the VM there was no relationship with $\operatorname{MED}(r=0.15, n=41, P=0.330$; Fig 5 B). Therefore, $\mathrm{EMG}_{\mathrm{MVT}}$ normalized to $\mathrm{M}_{\mathrm{MAX}}$ Area removed the influence of MED for the VM, but for the RF and VL MED still accounted for 19-23\% of the between-participant variability in sEMG amplitude.

Absolute $\mathrm{EMG}_{\mathrm{MVT}}$ had a mean $\mathrm{CV}_{\mathrm{B}}$ across the 3 muscles of $52.5 \%$ (VM 51.1\%; RF

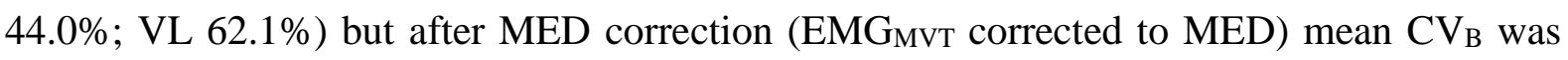
34.4\% (VM 34.2\%; RF 29.6\%; VL 39.5\%). Therefore, MED correction reduced the betweenparticipant variability by $35 \%$ (Table 2). The mean $\mathrm{CV}_{\mathrm{B}}$ of $\mathrm{EMG}_{\mathrm{MVT}}$ normalized by $\mathrm{M}_{\mathrm{MAx}} \mathrm{P}-$

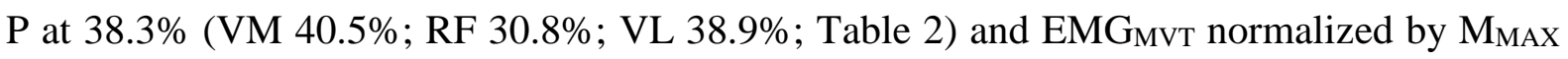
Area at 41.6\% (VM 44.4\%; RF 36.2\%; VL 44.2\%; Table 2) were also lower than absolute $\mathrm{EMG}_{\mathrm{MVT}}$, but greater than $\mathrm{EMG}_{\mathrm{MVT}}$ corrected to MED.

\section{DISCUSSION}


The present study assessed the influence of electrode location and MED on voluntary absolute and normalized (to M MAX P-P and Area) sEMG measurements. Absolute voluntary sEMG measurements varied by up to $42 \%$ with electrode location over the surface of the VL muscle; however, when normalized to $\mathrm{M}_{\mathrm{MAX}} \mathrm{P}-\mathrm{P}$, but not $\mathrm{M}_{\mathrm{MAX}}$ Area, there was no longer an effect of electrode location. As expected, voluntary sEMG amplitude for each of the 3 muscles was moderately correlated with MED (largely subcutaneous fat), which explained 31-38\% of the variance in EMG $_{M V T}$. Normalization of voluntary sEMG to $\mathrm{M}_{\mathrm{MAx}}$ parameters reduced but did not consistently remove the variance explained by MED (P-P up to 16\%, Area up to 23\%), Thus, $\mathrm{M}_{\mathrm{MAX}} \mathrm{P}-\mathrm{P}$ was the better normalization parameter, that removed the influence of electrode location and reduced but did not consistently or fully remove the influence of adiposity.

\section{Electrode location}

$\mathrm{EMG}_{\mathrm{MVT}}$ varied across the surface of the VL, being as much as $42 \%$ higher at some sites compared to others. Previous investigations using the trapezius muscle have also found voluntary sEMG amplitude to vary with location over the surface of the muscle ${ }^{18,19}$. MMAX PP showed a similar pattern to absolute voluntary EMG and consequently normalization of EMG $_{\text {MVT }}$ to $\mathrm{M}_{\mathrm{MAX}} \mathrm{P}-\mathrm{P}$ was independent of electrode location as both parameters changed proportionally across the surface of the VL. Hence this normalization method removed the effect of electrode location on voluntary sEMG amplitude. Furthermore, this finding suggests that any apparent differences in EMG amplitude across the surface of the muscle during MVCs are primarily due to differences in volume conduction and signal recording conditions, as shown by similar changes in $\mathrm{M}_{\mathrm{MAX}} \mathrm{P}-\mathrm{P}$, rather than any physiological differences in voluntary neuromuscular activation. However, the current study did not examine sub-maximum contractions, thus the possibility of regional differences in neuromuscular activation during 
low and moderate level contractions according to the specific task remains a distinct possibility 20,21

In contrast, $\mathrm{M}_{\mathrm{MAX}}$ Area showed a different pattern to absolute voluntary sEMG, such that when EMG $\mathrm{MVT}_{\mathrm{T}}$ was normalized to $\mathrm{M}_{\mathrm{MAX}}$ Area there remained a pronounced effect of electrode location with differences between sites of up to 57\%. Therefore, MMAX P-P normalization may be preferred when trying to remove/account for the issue of electrode location/re-location between test sessions or between investigators. Normalisation to $\mathrm{M}_{\mathrm{MAX}} \mathrm{P}$ P could theoretically have removed/reduced the influence of several between site confounding factors that may influence $\mathrm{EMG}_{\mathrm{MVT}}$, such as the amplitude of motor unit action potentials, adipose tissue thickness, skin and skin-electrode interface impedance. Although experiment 1 was not able to discriminate between these mechanisms by which $\mathrm{M}_{\mathrm{MAX}} \mathrm{P}-\mathrm{P}$ was effective.

$\mathrm{M}_{\text {MAX }}$ P-P qualitatively showed a similar pattern with electrode location as absolute voluntary sEMG, but not $\mathrm{M}_{\mathrm{MAX}}$ Area. The reason for these contrasting effects between $\mathrm{M}_{\mathrm{MAX}}$ P-P and Area, and thus also the greater efficacy of $\mathrm{M}_{\mathrm{MAX}} \mathrm{P}-\mathrm{P}$ for normalization purposes may reflect the differences in the nature of these measurements. $\mathrm{M}_{\mathrm{MAX}} \mathrm{P}-\mathrm{P}$ is a measure of amplitude, whereas $\mathrm{M}_{\mathrm{MAX}}$ Area is dependent on both amplitude and duration ${ }^{11}$, thus our finding might indicate that absolute $\mathrm{EMG}_{\mathrm{MVT}}$ depends primarily on signal amplitude rather than duration. Previous studies have only examined spatial distribution of M-wave amplitude, during submaximal stimulation and found the amplitude to be both higher ${ }^{22}$ and lower at distal sites ${ }^{23}$ in gastrocnemius. Sub-maximal stimulation selectively activates lower threshold motor units, and thus fibres, that could be concentrated in specific locations. In contrast, our findings are the first indication that $\mathrm{M}_{\mathrm{MAX}} \mathrm{P}-\mathrm{P}$ and Area vary with electrode location across the surface of the VL (albeit with different patterns).

Although experiment 1 involved 6 electrodes over the surface of the VL muscle, we deliberately chose a large superficial muscle, and selected the measurement sites to minimise 
the possibility of cross-talk from other muscles. Specifically, the measurement sites were a minimum of $3.5 \mathrm{~cm}$ distance, and typically $>4 \mathrm{~cm}$, from other muscles. Winter et al (1994) estimated that with a $3 \mathrm{~cm}$ distance between electrodes, cross-talk would account for $\sim 4 \%$ of the signal ${ }^{24}$. Therefore, it is possible that there could have been some small, limited cross-talk within our measurements, although our understanding is that there is no accepted analytical procedure to assess the extent of cross-talk within an EMG signal ${ }^{26}$.

\section{Muscle-Electrode distance}

In experiment 2, there were negative relationships between EMGMVT and MED in all the three muscles ( $r=-0.56$ to -0.62 ), with MED explaining 31-38\% of the variance even within this relatively lean cohort $(\mathrm{BMI} \leq 24)$. Previous investigators identified similar negative relationships between absolute voluntary sEMG amplitude and MED measure by ultrasound (r $=0.57)^{7}$ or skinfold thickness $\left(r=0.90^{26}\right.$ and $\left.r=0.67^{7}\right)$. The relationship between absolute sEMG amplitude and MED can be explained by the high electrical resistance of body fat 8,27 which acts as a low pass filter reducing the signal amplitude ${ }^{28}$. Specifically, more subcutaneous tissue between the sEMG electrode and the muscle would provide more electrical resistance. Thus, tissue thickness between the electrode and the active muscle fibers has a pronounced influence on sEMG amplitude.

$\mathrm{M}_{\mathrm{MAX}}$ normalization substantially reduced, but did not consistently remove the effect of MED on EMG amplitude with up to $16 \%$ (M MAX P-P) or 23\% (M $\mathrm{M}_{\mathrm{MAX}}$ Area) of the variability in normalized voluntary sEMG still explained by MED. Therefore, whilst $\mathrm{M}_{\mathrm{MAX}}$ normalization was certainly an improvement on absolute values it was only partially effective at removing the confounding effects of differences in MED between participants. Therefore, it is possible that a measured MED is more effective at fully removing the influence of adipose tissue thickness, than $\mathrm{M}_{\mathrm{MAX}}$ parameters when comparing participants. In addition, EMG $\mathrm{MVT}_{\mathrm{T}}$ corrected 
to MED produced lower between-participant variability $\left(\mathrm{CV}_{\mathrm{B}} 34 \%\right)$ than absolute $\mathrm{EMG}_{\mathrm{MVT}}$ (53\%) or $\mathrm{EMG}_{\mathrm{MVT}}$ normalized to $\mathrm{M}_{\mathrm{MAX}} \mathrm{P}-\mathrm{P}$ (38\%) or $\mathrm{M}_{\mathrm{MAX}}$ Area (42\%) suggesting that MED correction may be the most effective method at reducing the between-participant variability introduced by volume conduction and signal recording conditions. Consequently, when comparing individuals with substantial differences in MED, or comparing repeated measurements that may involve changes in MED after an intervention (e.g. exercise training or weight loss) it is recommended to normalise voluntary sEMG measurements, either to $\mathrm{M}_{\mathrm{MAX}}$ P-P or preferably MED (e.g. ${ }^{29}$ ). It is unclear why voluntary sEMG recordings and MMAX parameters do not change in proportion with MED, but it is likely to be due to the fact that voluntary sEMG is a summation pattern from the electrical activity of numerous muscle fibres ${ }^{2}$ that propagates through the surrounding tissues in a different manner to a synchronous evoked M-wave.

Any variability in electrode location and orientation between participants could have been a contributory factor to the observed between-participant variability in voluntary sEMG recordings. Whilst the current investigation examined MED correction in relation to betweenparticipant variability in voluntary sEMG, as far as we are aware it is currently unknown how MED correction compares to $\mathrm{M}_{\mathrm{MAX}}$ normalisation for different electrode locations and future work should address this question to better understand the merits of these normalisation procedures. Moreover, it is recommended that future work more carefully examine the reliability and validity of voluntary sEMG amplitude measurements corrected to MED as this correction procedure has had relatively little attention despite the well-known confounding influence of adiposity ${ }^{6-8}$.

In conclusion, electrode location across the surface of the VL had a pronounced effect on voluntary sEMG amplitude during MVCs, and this was removed by normalization to $\mathrm{M}_{\mathrm{MAX}}$ P-P, but not $\mathrm{M}_{\mathrm{MAX}}$ Area. The moderate relationship between adiposity (MED) and voluntary 
sEMG amplitude ( $\mathrm{R}^{2}=0.31$ up to 0.38 ) was reduced but not consistently removed by $\mathrm{M}_{\mathrm{MAX}}$ normalization (up to $\mathrm{R}^{2}=0.16\left[\mathrm{P}-\mathrm{P}\right.$ ] and $\mathrm{R}^{2}=0.23$ [Area]). MMAX P-P was the better normalization parameter that removed the influence of electrode location and substantially reduced but did not consistently or fully remove the influence of adiposity.

\section{PERSPECTIVES}

Whilst surface electromyography (sEMG) measurements are widely used in physiological and biomechanical assessments and research studies, the amplitude of these recordings are known to be influenced by both electrode position and subcutaneous adipose tissue thickness. The present study quantified the influence of electrode position and adipose tissue thickness and examined the possibility that normalization to evoked maximum M-wave ( $\left.\mathrm{M}_{\mathrm{MAX}}\right)$ parameters may remove the influence of these factors. As expected electrode location and adiposity both had a pronounced influence on voluntary sEMG amplitude. Normalisation of these measurements to $\mathrm{M}_{\mathrm{MAx}}$ peak-to-peak removed the influence of electrode location and reduced, but did not consistently remove the influence of subcutaneous adiposity. Thus, normalization to $\mathrm{M}_{\mathrm{MAX}}$ peak-to-peak may help to reduce the influence of these potential confounding factors when comparing measurements within- or between-participants in clinical assessments or research studies. However, to fully remove the influence of adipose tissue thickness may require direct measurements of this parameter beneath the recording electrodes.

\section{REFERENCES}

1. De Luca CJ. The Use of Surface Electromyography in Biomechanics. J Appl Biomech 1997;13:135-163.

2. Raez MBI, Hussain MS, Mohd-Yasin F. Techniques of EMG signal analysis: 
detection, processing, classification and applications. Biol Proced Online 2006;8:1135.

3. Farina D, Madeleine P, Graven-Nielsen T, Merletti R, Arendt-Nielsen L. Standardising surface electromyogram recordings for assessment of activity and fatigue in the human upper trapezius muscle. Eur J Appl Physiol 2002;86:469-478.

4. Rainoldi a, Melchiorri G, Caruso I. A method for positioning electrodes during surface EMG recordings in lower limb muscles. J Neurosci Methods 2004;134:37-43.

5. Beck TW, Housh TJ, Cramer JT, Weir JP. The effects of electrode placement and innervation zone location on the electromyographic amplitude and mean power frequency versus isometric torque relationships for the vastus lateralis muscle. $\mathrm{J}$ Electromyogr Kinesiol 2008;18:317-328.

6. Farina D, Rainoldi A. Compensation of the effect of sub-cutaneous tissue layers on surface EMG: a simulation study. Med Eng Phys 1999;21:487-497.

7. Nordander C, Willner J, Hansson GÅ, Larsson B, Unge J, Granquist L, Skerfving S. Influence of the subcutaneous fat layer, as measured by ultrasound, skinfold calipers and BMI, on the EMG amplitude. Eur J Appl Physiol 2003;89:514-519.

8. Petrofsky J. The effect of the subcutaneous fat on the transfer of current through skin and into muscle. Med Eng Phys 2008;30:1168-1176.

9. Buckthorpe MW, Hannah R, Pain TG, Folland JP. Reliability of neuromuscular measurements during explosive isometric contractions, with special reference to electromyography normalization techniques. Muscle Nerve 2012;46:566-576.

10. Papaiordanidou M, Mustacchi V, Stevenot JD, Vanoncini M, Martin A. Spinal and 
supraspinal mechanisms affecting torque development at different joint angles. Muscle Nerve 2016;53:626-632.

11. Rodriguez-Falces J, Duchateau J, Muraoka Y, Baudry S. M-wave potentiation after voluntary contractions of different durations and intensities in the tibialis anterior. $\mathrm{J}$ Appl Physiol 2015;118:953-964.

12. Gandevia SC. Spinal and supraspinal factors in human muscle fatigue. Physiol Rev 2001;81:1725-1789.

13. Balshaw TG, Fry A, Maden-Wilkinson TM, Kong PW, Folland JP. Reliability of quadriceps surface electromyography measurements is improved by two vs. single site recordings. Eur J Appl Physiol 2017;117:1085-1094.

14. Barbero M, Merletti R, Rainoldi A. Atlas of Muscle Innervation Zones. Milano: Springer Milan; 2012. 142 p.

15. Beck TW, Housh TJ, Cramer JT, Weir JP. The effect of the estimated innervation zone on EMG amplitude and center frequency. Med Sci Sports Exerc 2007;39:1282-1290.

16. Cohen J. Statistical power analysis for the behavioral sciences. Stat Power Anal Behav Sci 1988;2nd:567.

17. Moya-Laraño J, Corcobado G. Plotting partial correlation and regression in ecological studies. Web Ecol 2008;8:35-46.

18. Jensen C, Vasseljen O, Westgaard RH. The influence of electrode position on bipolar surface electromyogram recordings of the upper trapezius muscle. Eur J Appl Physiol Occup Physiol 1993;67:266-273.

19. McLean L, Chislett M, Keith M, Murphy M, Walton P. The effect of head position, 
electrode site, movement and smoothing window in the determination of a reliable maximum voluntary activation of the upper trapezius muscle. J Electromyogr Kinesiol 2003;13:169-180.

20. Staudenmann D, Roeleveld K, Stegeman DF, van Dieen JH. Methodological aspects of SEMG recordings for force estimation--a tutorial and review. J Electromyogr Kinesiol 2010;20:375-387.

21. Watanabe K, Kouzaki M, Moritani T. Task-dependent spatial distribution of neural activation pattern in human rectus femoris muscle. J Electromyogr Kinesiol 2012;22:251-258.

22. Vieira TM, Botter A, Minetto MA, Hodson-Tole EF. Spatial variation of compound muscle action potentials across human gastrocnemius medialis. J Neurophysiol 2015;114:1617-1627.

23. Hodson-Tole EF, Loram ID, Vieira TMM. Myoelectric activity along human gastrocnemius medialis: Different spatial distributions of postural and electrically elicited surface potentials. J Electromyogr Kinesiol 2013;23:43-50.

24. Winter DA, Fuglevand AJ, Archer SE. Crosstalk in surface electromyography: Theoretical and practical estimates. J Electromyogr Kinesiol 1994;4:15-26.

25. Farina D, Merletti R, Enoka RM. The extraction of neural strategies from the surface EMG: an update. J Appl Physiol 2014;117:1215-1230.

26. Hemingway MA, Biedermann HJ, Inglis J. Electromyographic recordings of paraspinal muscles: Variations related to subcutaneous tissue thickness. Biofeedback Self Regul 1995;20:39-49. 
27. Lowery MM, Stoykov NS, Taflove A, Kuiken TA. A multiple-layer finite-element model of the surface EMG signal. IEEE Trans Biomed Eng 2002;49:446-454.

28. Farina D, Merletti R, Indino B, Nazzaro M, Pozzo M. Surface EMG crosstalk between knee extensor muscles: experimental and model results. Muscle Nerve 2002;26:681695.

29. Clark DJ, Patten C, Reid KF, Carabello RJ, Phillips EM, Fielding RA. Impaired Voluntary Neuromuscular Activation Limits Muscle Power in Mobility-Limited Older Adults. Journals Gerontol Ser A Biol Sci Med Sci 2010;65A:495-502. 


\section{Figure Legends}

Fig. 1 - Electrode placement over the vastus lateralis (VL) for Experiment one (Spatial Location). Anterior (A) and posterior (P) rows of electrodes were placed at $\sim 30 \%$ and $~ 70 \%$ of the distance between the superficial anterior and posterior borders of the VL (respectively) and numbered from distal to proximal.

Fig. 2 - An example ultrasound image from one participant for the measurement of muscle electrode distance (MED) in Experiment two. Measurement of MED over the vastus lateralis (VL) at $60 \%$ of the thigh length.

Fig. 3 - Experiment one - Spatial location. Absolute sEMG measurements from 6 recording sites over the surface of the vastus lateralis (VL) during maximum voluntary torque production

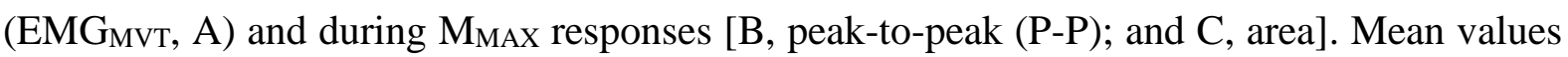
are shown for $n=10$. Post-hoc differences between sites are indicated as: * higher than P2 and $\mathrm{P} 3(\mathrm{P} \leq 0.036), \neq$ higher than $\mathrm{P} 3(\mathrm{P} \leq 0.046)$, § higher than $\mathrm{P} 2(\mathrm{P} \leq 0.041)$.

Fig. 4 - Experiment one - Electrode spatial location. EMG voluntary torque) normalized to (A) $\mathrm{M}_{\mathrm{MAX}}$ peak-to-peak (P-P) or (B) $\mathrm{M}_{\mathrm{MAX}}$ Area for 6 recording sites over the surface of the vastus lateralis. Mean values are shown for $n=10$. Posthoc differences between sites are indicated as: \# higher than P3 $(\mathrm{P} \leq 0.014)$.

Fig. 5 - Experiment two - muscle-electrode distance $(n=41)$. Relationship between muscleelectrode distance (MED) and three different measures of surface EMG amplitude during maximum voluntary torque (MVT) production: A, absolute EMG ${ }_{M V T}$; B, EMGMVT normalized to $\mathrm{M}_{\mathrm{MAX}}$ peak-to-peak (P-P); C, $\mathrm{EMG}_{\mathrm{MVT}}$ normalized to $\mathrm{M}_{\mathrm{MAX}}$ Area; for individual muscles [rectus femoris (RF); vastus medialis (VM); and vastus lateralis (VL); $n=41$ ]. 
Table 1 - surface EMG recorded at the six sites over the vastus lateralis (VL) during isometric knee extension maximum voluntary torque (MVT) production (absolute and normalized to $\mathrm{M}_{\mathrm{MAX}}$ Area and peak-to-peak [P-P]), and absolute evoked $\mathrm{M}_{\mathrm{MAX}}$ responses (M $\mathrm{M}_{\mathrm{MAX}}$ Area and P-P). Data are mean $\pm \mathrm{SD}(n=10)$.

\begin{tabular}{|c|c|c|c|c|c|}
\hline VL Sites & $\begin{array}{c}\mathrm{EMG}_{\mathrm{MVT}} \\
(\mathrm{mV})\end{array}$ & $\begin{array}{l}\mathrm{M}_{\mathrm{MAX}} \text { Area } \\
(\mathrm{mV} . \mathrm{s})\end{array}$ & $\begin{array}{l}\mathrm{M}_{\mathrm{MAX}} \mathrm{P}-\mathrm{P} \\
(\mathrm{mV})\end{array}$ & $\begin{array}{l}\text { Normalized EMG } \mathrm{MVVT}_{\mathrm{T}} \\
\left(\mathrm{M}_{\mathrm{MAX}} \text { Area.s } \mathrm{s}^{-1}\right)\end{array}$ & $\begin{array}{c}\text { Normalized EMG } \mathrm{MMVT}_{\mathrm{T}} \\
\left(\% \mathrm{M}_{\mathrm{MAX}} \mathrm{P}-\mathrm{P}\right)\end{array}$ \\
\hline A1 & $0.22 \pm 0.06$ & $0.019 \pm 0.004$ & $2.8 \pm 0.7$ & $12.3 \pm 2.2$ & $8.5 \pm 2.9$ \\
\hline A2 & $0.21 \pm 0.06$ & $0.018 \pm 0.006$ & $2.9 \pm 0.9$ & $12.5 \pm 3.1$ & $7.7 \pm 1.9$ \\
\hline A3 & $0.22 \pm 0.10$ & $0.021 \pm 0.009$ & $3.0 \pm 1.6$ & $11.7 \pm 6.3$ & $8.7 \pm 4.8$ \\
\hline $\mathrm{P} 1$ & $0.18 \pm 0.05$ & $0.014 \pm 0.004$ & $2.3 \pm 0.7$ & $13.8 \pm 2.3$ & $8.3 \pm 1.8$ \\
\hline P2 & $0.14 \pm 0.03$ & $0.010 \pm 0.003$ & $1.4 \pm 0.3$ & $13.5 \pm 4.1$ & $9.8 \pm 2.4$ \\
\hline P3 & $0.13 \pm 0.03$ & $0.015 \pm 0.004$ & $1.9 \pm 0.7$ & $8.8 \pm 3.9$ & $7.6 \pm 4.0$ \\
\hline
\end{tabular}


Table 2 - surface EMG variables recorded over the rectus femoris (RF), vastus medialis (VM) and vastus lateralis (VL) during isometric knee extension maximum voluntary torque (MVT) production: absolute MMG $_{\mathrm{MVT}}$; EMG $\mathrm{MVT}_{\mathrm{M}}$ corrected for muscle-

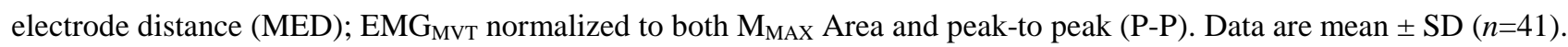

\begin{tabular}{|c|c|c|c|c|c|c|}
\hline EMG Variables & $\mathrm{RF}$ & $\mathrm{CV}_{\mathrm{B}}(\%)$ & VM & $\mathrm{CV}_{\mathrm{B}}(\%)$ & VL & $\mathrm{CV}_{\mathrm{B}}(\%)$ \\
\hline $\mathrm{EMG}_{\mathrm{MVT}}(\mathrm{mV})$ & $0.17 \pm 0.09$ & 51.1 & $0.22 \pm 0.10$ & 44.0 & $0.15 \pm 0.09$ & 62.1 \\
\hline $\mathrm{EMG}_{\mathrm{MVT}}(\mathrm{mV}$, corrected for MED) & $0.17 \pm 0.05$ & 29.6 & $0.22 \pm 0.07$ & 34.2 & $0.15 \pm 0.06$ & 39.5 \\
\hline Normalized EMG ${ }_{\text {MVT }}\left(\mathrm{M}_{\mathrm{MAX}}\right.$ Area.s $\left.^{-1}\right)$ & $13.7 \pm 4.8$ & 36.2 & $12.7 \pm 5.7$ & 44.4 & $10.9 \pm 4.9$ & 44.2 \\
\hline Normalized EMG MVT $_{\text {(\%M }}$ MAX P-P) & $9.5 \pm 2.9$ & 30.8 & $8.7 \pm 3.5$ & 40.5 & $8.0 \pm 3.1$ & 38.9 \\
\hline
\end{tabular}




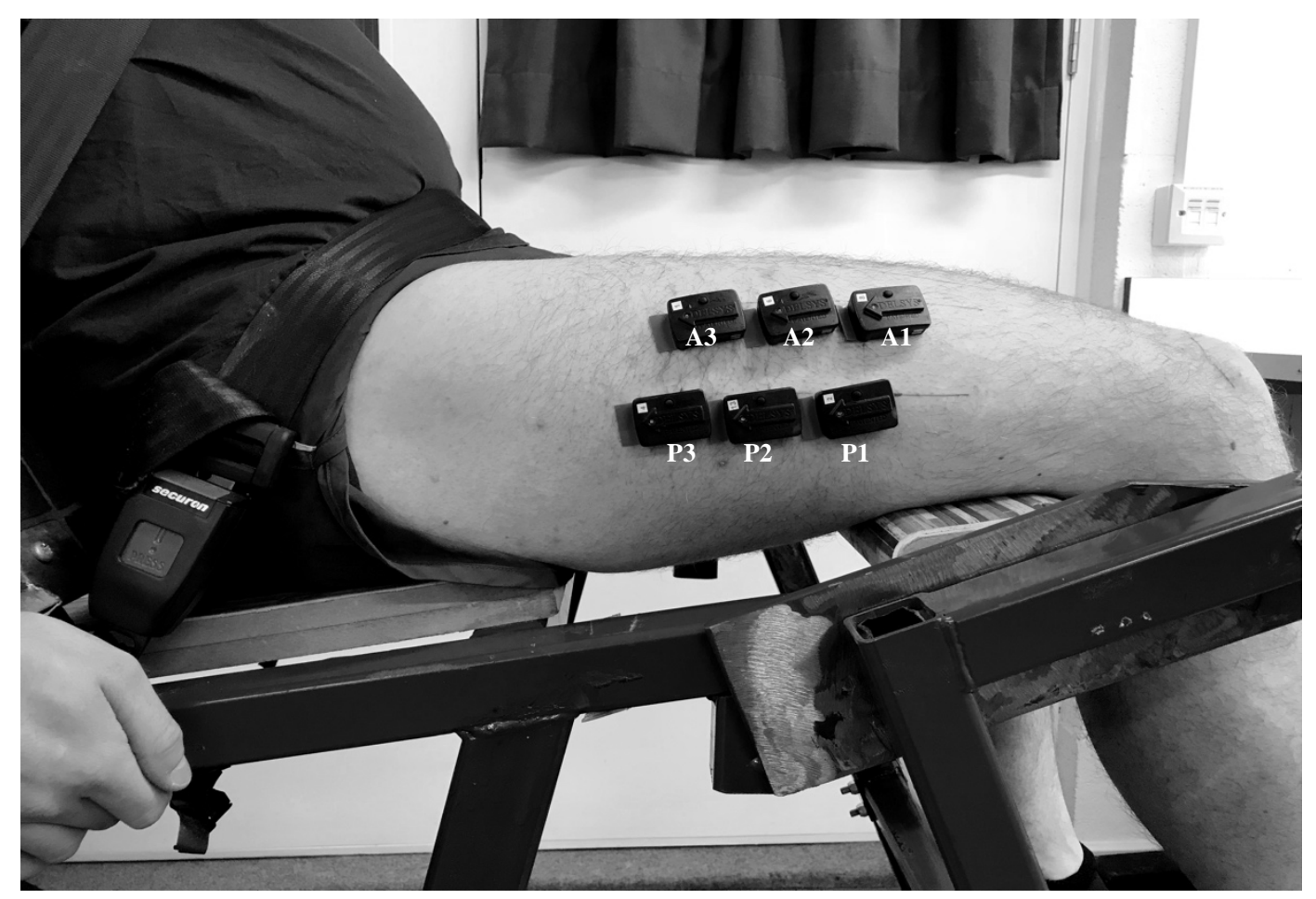

[Fig.1] 


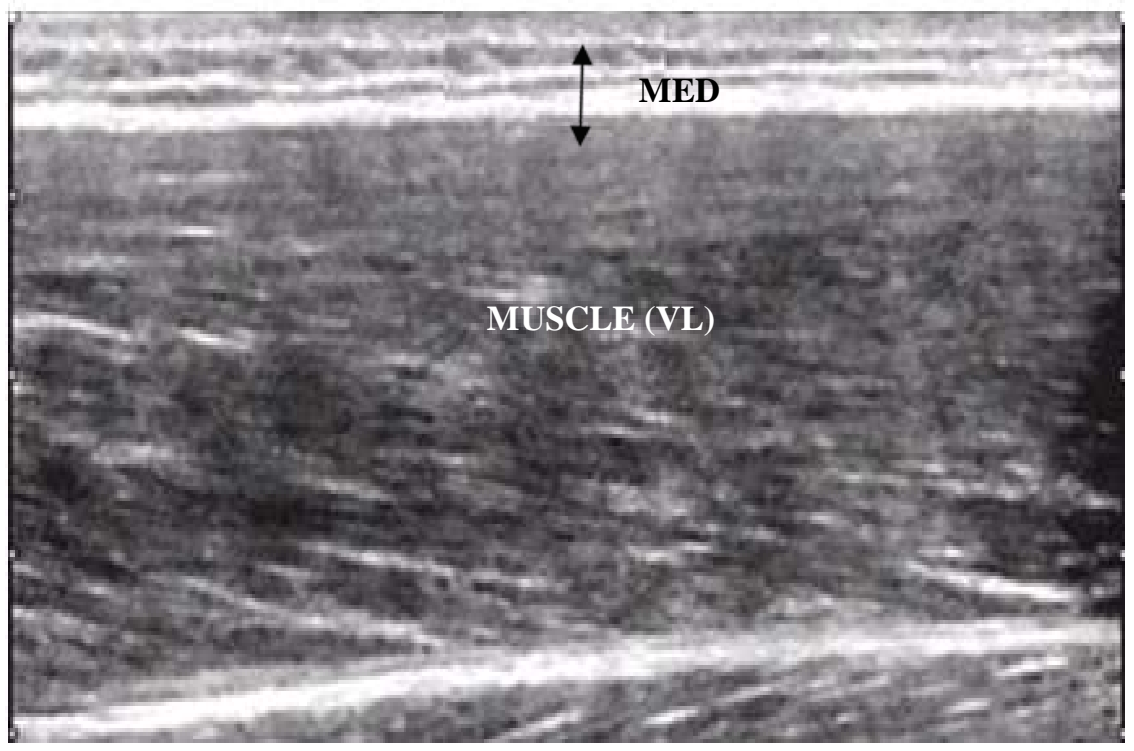

[Fig. 2] 
A
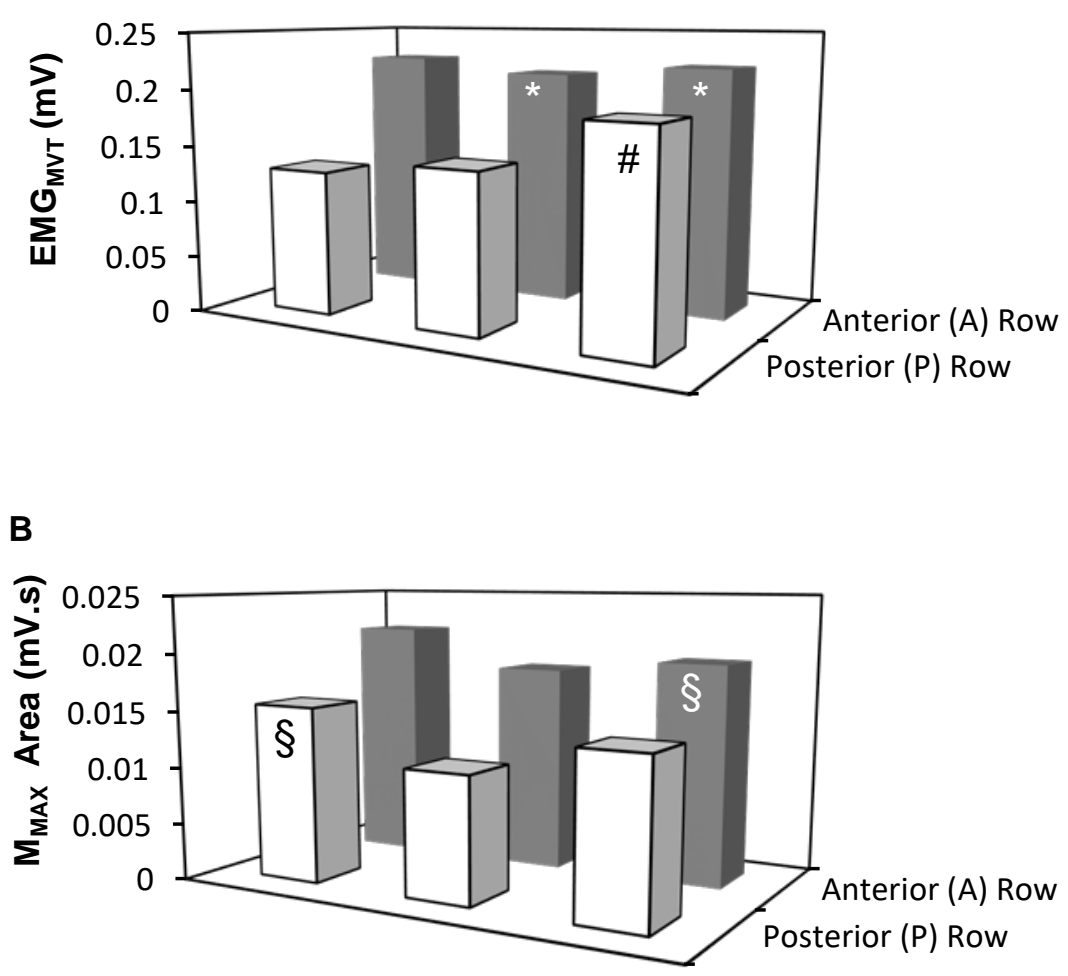

C

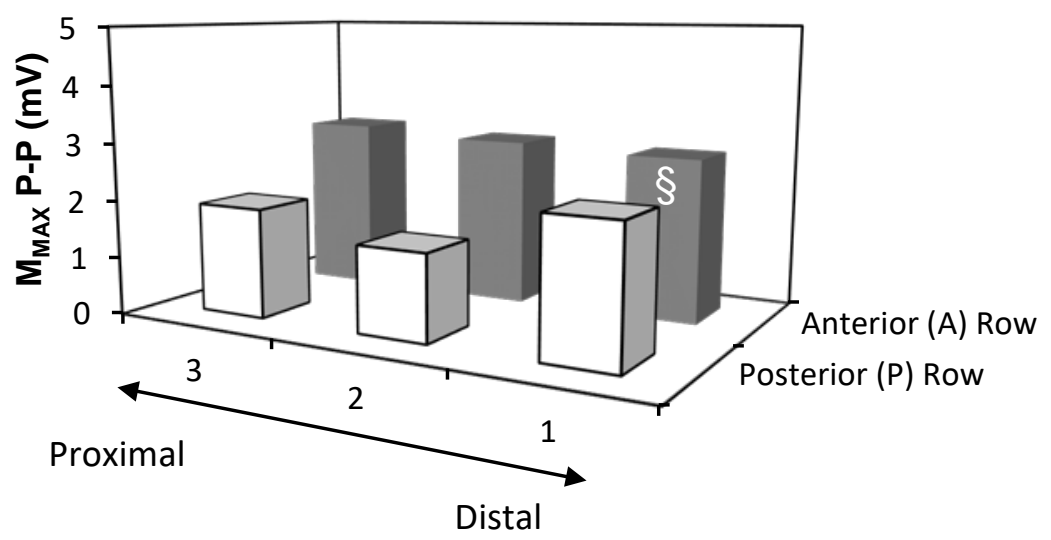

[Fig. 3] 


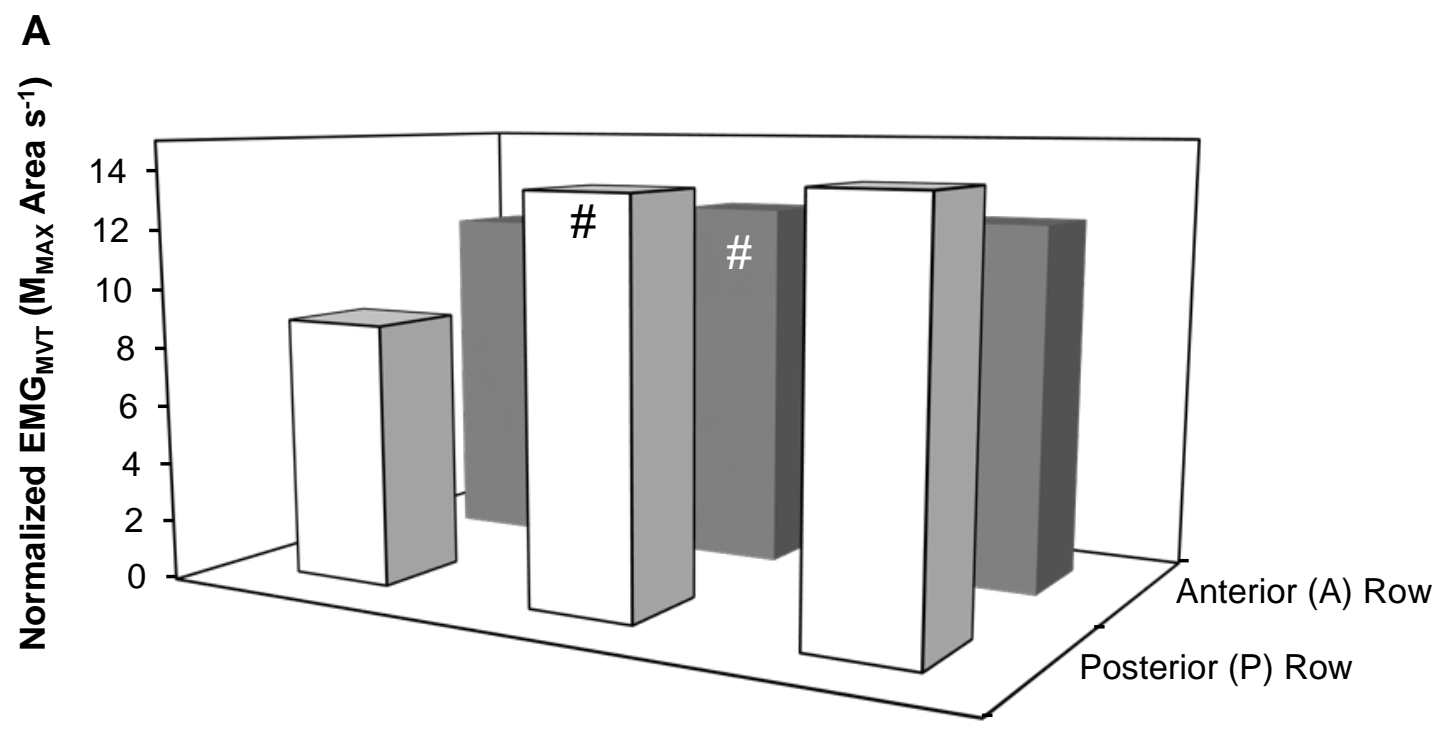

B

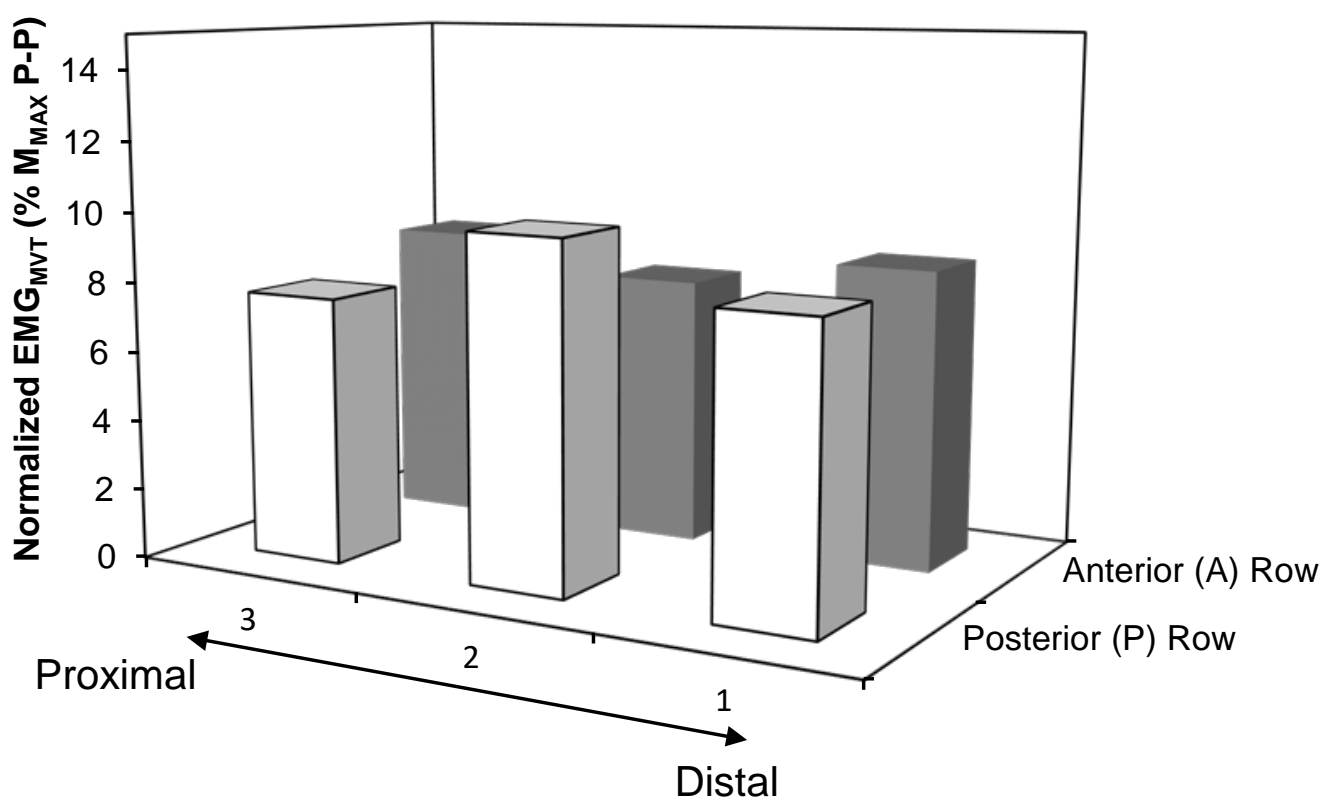

[Fig. 4] 
RMS EMGMVT

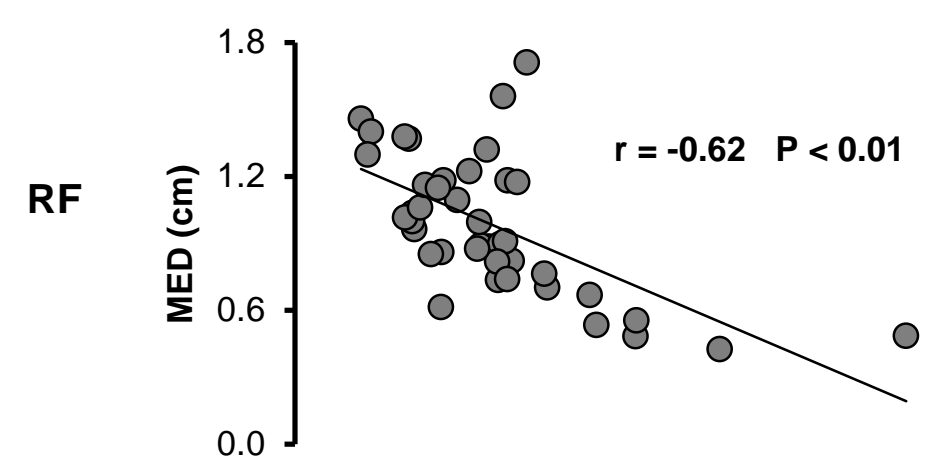

VM

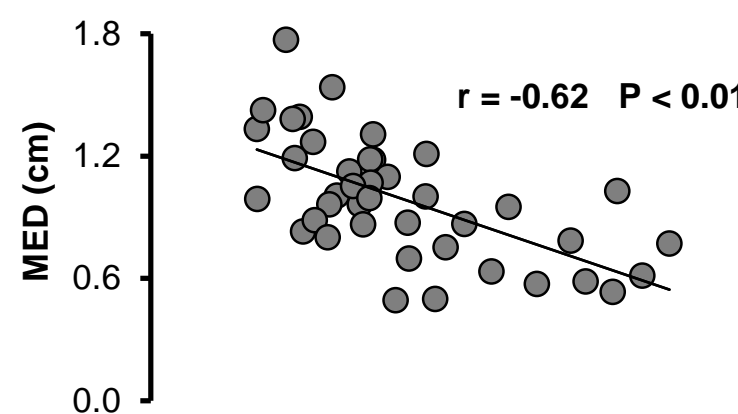

VL

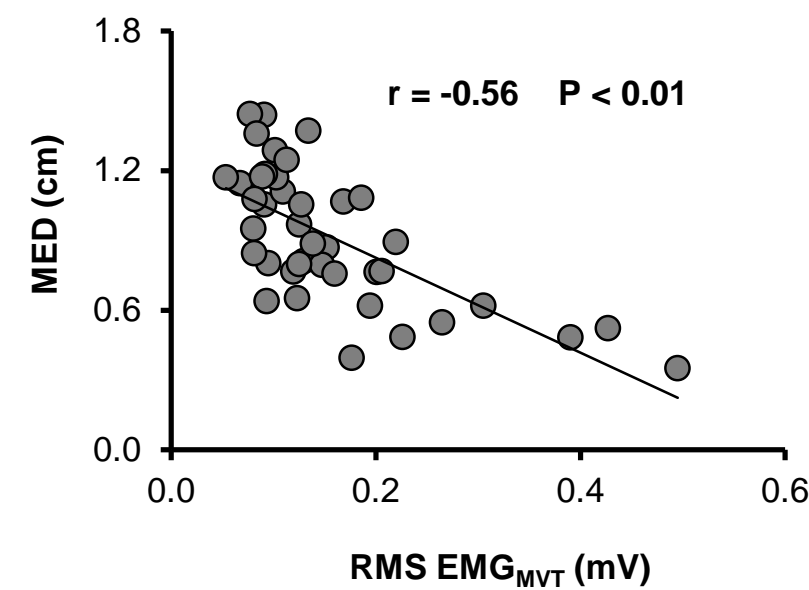

Normalized EMG ${ }_{\text {Mvт }}\left(\% M_{\text {max }}\right.$ P-P)
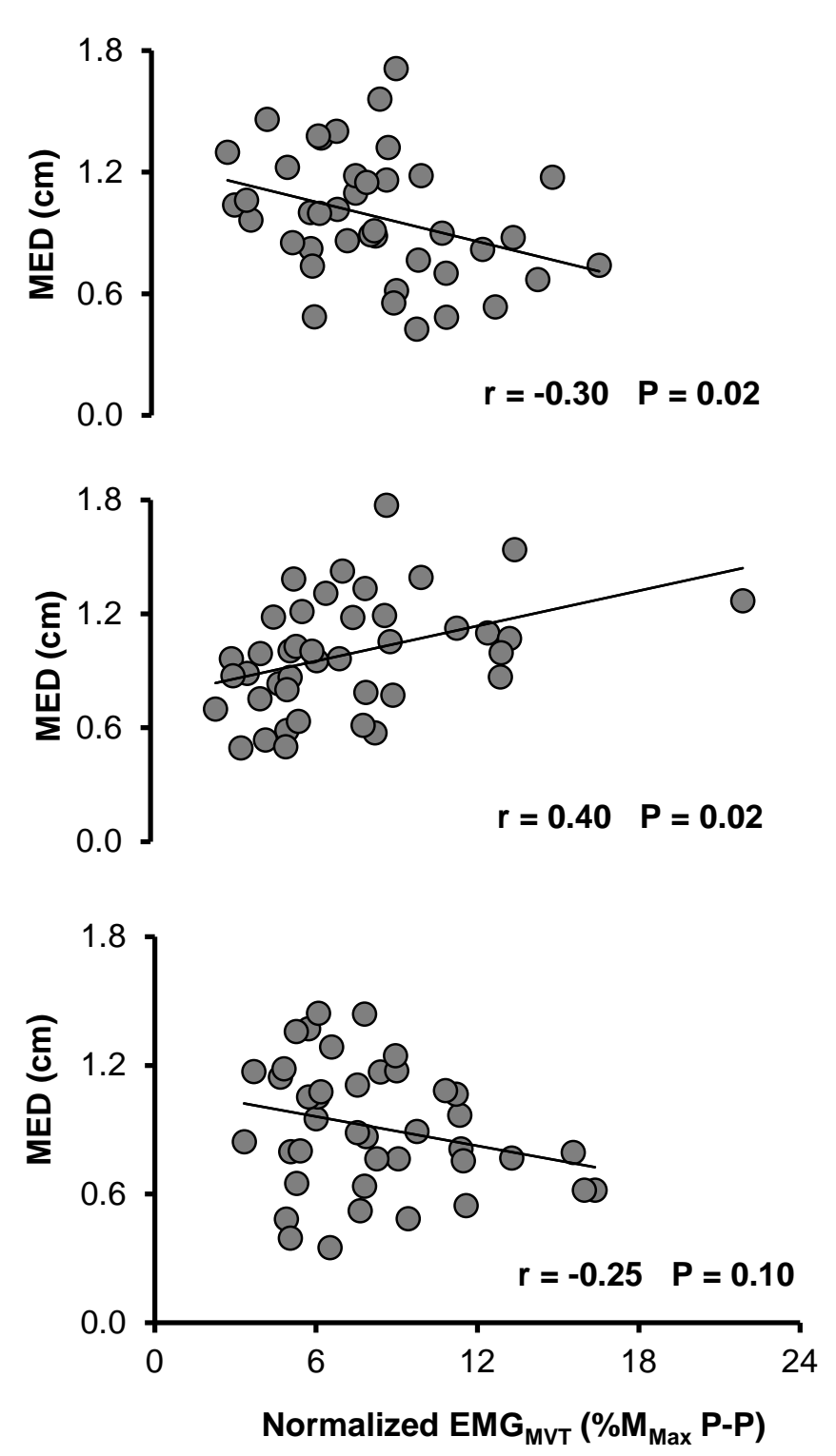

Normalized EMGмvт (MmAx Area.s ${ }^{-1}$ )
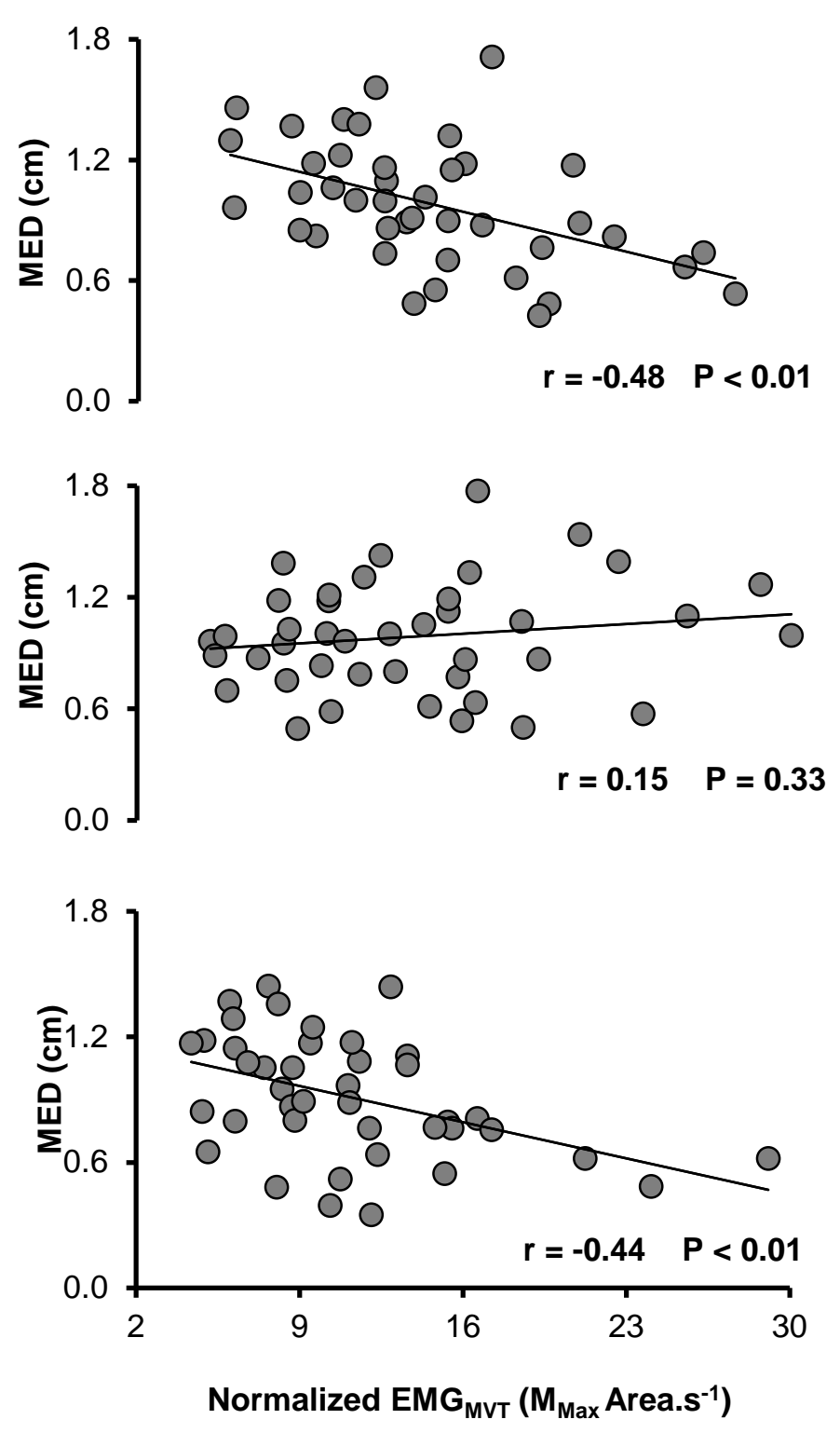
[Fig. 5] 
